\title{
DETERMINAÇÃO DA DOSE DE RADIAÇÃO GAMA PARA REDUZIR A POPULAÇÃO DE Salmonella SPP EM CARNE DE FRANGO'
}

\author{
A.F. SANTOS ${ }^{2}$, D.M. VIZEU ${ }^{2}$, M.T. DESTRO ${ }^{2}$, B.D.G.M. FRANCO ${ }^{2}$, M. LANDGRAF ${ }^{2, *}$
}

\begin{abstract}
RESUMO
O consumo de carne de frango contaminada com Salmonella é uma causa importante de salmonelose em todo o mundo. Essa doença transmitida por alimentos, é um problema de saúde pública e causa de perdas econômicas substanciais. O processo de irradiação é um método eficiente de conservação de alimentos por reduzir o número de microrganismos patogênicos e deteriorantes, sem que as caracteristicas organolépticas e nutricionais do alimento sejam alteradas significativamente. Os objetivos desta pesquisa foram determinar o valor $\mathrm{D}_{10}$ de Salmonella Typhimurium ATCC 14028, inoculada em sobrecoxas de frango, e recomendar uma dose de radiação para ser aplicada a esse alimento a fim de torná-lo seguro do ponto de vista microbiológico. O valor $\mathrm{D}_{10}$ foi calculado a partir da curva de sobreviventes dessa bactéria em sobrecoxas de frango, após terem sido expostas às doses de $0 \mathrm{kGy}$; 0,1kGy; 0,2kGy; $0,3 \mathrm{kGy}$; 0,5kGy; 0,6kGy; 0,7kGy e 0,8kGy. O valor $\mathrm{D}_{10}$ variou de 0,241kGy a 0,480kGy. Considerando o maior valor $\mathrm{D}_{10}$ e o maior nivel de contaminação de Salmonella spp encontrado em sobrecoxas de frango - 0,4NMP/g - adquiridas em feiras livres da cidade de São Paulo, a dose de radiação gama recomendada para garantir a segurança do produto em relação à presença de Salmonella spp é de 3,8kGy.

Palavras-chave: Salmonella spp; Salmonella Typhimurium; frango; radiação ionizante; irradiação de alimento; radiação gama.
\end{abstract}

\section{SUMMARY}

DETERMINATION OF GAMMA RADIATION DOSES TO REDUCE Salmonella spp IN CHIKEN MEAT. The consumption of chicken meat contaminated with Salmonella spp is an important cause of salmonellosis worldwide. This food-borne disease is a public health problem and causes substantial economical loss. Irradiation process is an effective method for food preservation because it causes no significant change in organoleptic and nutritional food characteristics and destroys pathogenic and spoilage microorganisms. $\mathrm{D}_{10}$ values were calculated through the number of survivors for S. Typhimurium ATCC 14028, inoculated in chicken thighs, after being irradiated with different doses of gamma radiation - $0.0 \mathrm{kGy} ; 0.1 \mathrm{kGy} ; 0.2 \mathrm{kGy} ; 0.3 \mathrm{kGy} ; 0.5 \mathrm{kGy} ; 0.7 \mathrm{kGy}$ and $0.8 \mathrm{kGy} . \mathrm{D}_{10}$ value ranged from $0.241 \mathrm{kGy}$ to $0.480 \mathrm{kGy}$. Considering the highest $\mathrm{D}_{10}$ value and the contamination level of Salmonella spp in chicken thighs acquired in São Paulo free markets - 0.4MPN/g -, the radiation dose recommended for this product in order to assure safety in relation to the presence of Salmonella spp is $3.8 \mathrm{kGy}$.

Keywords: Salmonella spp; chicken; food irradiation; gamma radiation.

\section{1 - INTRODUÇÃO}

Com o intuito de assegurar a qualidade de um alimento, tanto do ponto de vista de saúde pública como para aumentar a sua vida-de-prateleira, vários são os métodos disponiveis para as indústrias de alimentos. A maioria deles, como por exemplo, refrigeração, congelamento, desidratação, fermentação e adição de conservantes agem prevenindo ou inibindo o crescimento dos microrganismos. Outros, por outro lado, agem inativando os microrganismos. Entre estes últimos, podem ser citados a pasteurização, a esterilização e a irradiação. Na irradiação, o processo mais versátil é o que aplica a radiação ionizante [1].

A irradiação é um método de pasteurização a frio (sem produção de aquecimento) utilizado para controlar doenças de origem alimentar causadas por microrganismos patogênicos, parasitas, especialmente em alimentos que são consumidos crus ou parcialmente processados [19], além de apresentar característica única de poder ser aplicada em alimentos congelados [9].

Recebido para publicação em 20/09/2001. Aceito para publicação em 14/01/2003 (000739).

2. Departamento de Alimentos e Nutrição Experimental, Faculdade de Ciências Farmacêuticas, USP. Av. Prof. Lineu Prestes, 580 B. 14. CEP 05508-900. São Paulo-SP. E-mail: landgraf@usp.br

* A quem a correspondência deve ser enviada.
As fontes de radiação ionizante empregadas em alimentos são isótopos radioativos emissores de radiação gama, como o ${ }^{60} \mathrm{Co}$ e ${ }^{137} \mathrm{Cs}$, os raios $\mathrm{X}$ gerados por máquinas que trabalham com energia de até $5 \mathrm{MeV}$ e elétrons gerados por máquinas que trabalham com energia de até $10 \mathrm{MeV}$. A radiação gama pode ser utilizada na inibição de brotamento de batatas e cebolas, para retardar o amadurecimento de frutas e vegetais e para a pasteurização e esterilização de vários produtos alimentícios devido a sua alta capacidade de penetração [8]. Por outro lado, a irradiação produzida pelos feixes de elétrons e raios X apresentam baixo poder de penetração o que dificulta seu emprego na área de alimentos.

Em 1990, o Food and Drug Administration (FDA) aprovou a irradiação de frango para controlar patógenos de origem alimentar [24]. Em 1997, esse mesmo orgão aprovou o uso da radiação em carnes vermelhas refrigeradas e congeladas. Atualmente, existem petições junto ao órgão solicitando o uso da radiação ionizante em frutos do mar. GOULD [11] relata que a Ásia e a Europa já usam correntemente a irradiação, principalmente para camarão. No Brasil, Resolução RDC no 21 de 26/01/ 2001 aprovou o "Regulamento Técnico para a Irradiação de Alimentos" que permite a irradiação de qualquer alimento com a condição de que a dose máxima absorvida seja inferior àquela que comprometa as propriedades funcionais e/ou os atributos sensoriais do alimento e que a dose mínima absorvida seja suficiente para alcançar o objetivo pretendido [2]. 
A irradiação de alimentos com doses de 2-7kGy, dependendo da condição de irradiação (temperatura durante o processo, por exemplo) e do alimento, pode reduzir significativamente microrganismos patogênicos incluindo tanto os já muito conhecidos como Salmonella spp, Staphylococcus aureus como os emergentes como E. coli O157:H7 [10].

Apesar do aparecimento de novos microrganismos no cenário das doenças transmitidas por alimentos, Salmonella ainda ocupa lugar de destaque nas estatísticas epidemiológicas dessas doenças. De todos os microrganismos estudados por TODD [34], Salmonella spp foi, nos Estados Unidos da América, o agente de doença bacteriana de origem alimentar que apresentou o maior custo: 4 bilhões de dólares.

Em um levantamento realizado pelo PUBLIC HEALTH LABORATORY SERVICE DO REINO UNIDO [26], no período de 1992 a 1998 , do total de 4012 surtos de doenças infecciosas intestinais ocorridas na Inglaterra e País de Gales, Salmonella spp foi o mais freqüente microrganismo incriminado, sendo responsável por 879 (22\%) surtos.

Na América Latina, Salmonella spp foi a segunda causa de doenças bacterianas veiculadas por alimentos no período de 1995 a 1998. Dos surtos causados por bactérias, Salmonella spp foi responsável por 324 (33,4\%), ficando atrás apenas de Staphylococcus sp que foi o agente causal de 342 surtos $(35,2 \%)$ [22].

No periodo entre 1985 e 1996, GELLI et al. [10] verificaram que das cepas de Salmonella isoladas no Estado de São Paulo, 34\% eram provenientes de carnes vermelhas e derivados, $31,5 \%$ originadas de aves e derivados e $10,6 \%$ encontradas em ovos e derivados. As demais cepas estavam presentes em diferentes alimentos.

JAKABI et al. [16] constataram que no período de 1994 a 1997, na Grande São Paulo, do total relatado de enfermidades transmitidas por alimentos, 72,2\% foram causadas por Salmonella spp. Das amostras de alimentos ou água relacionadas a estes surtos, $47 \%$ eram ovos e preparações à base de ovos, 13\% carnes, 13\% água, $8,7 \%$ grãos, $8,7 \%$ leite reconstituído, $4,3 \%$ salgadinho e 4,3\% batata cozida.

Segundo HELSON [13] os alimentos julgados mais importantes na transmissão de Salmonella são aves e produtos à base de aves e ovos e produtos a base de ovos e a estratégia considerada mais eficiente para a redução desta bactéria destes produtos é a irradiação e aplicação do sistema HACCP.

A maior vantagem do processo de irradiação está nas poucas alterações que ele provoca nos componentes dos alimentos. Além disso, muitas dessas alterações ocorrem em outros processos como congelamento, envasamento ou desidratação.

A radiorresistência de um organismo é indicada pela dose, medida em kilogray - kGy (1Gy = 1 Joule $/ \mathrm{kg})$ necessária para inativar $90 \%$ da população, ou seja, seu valor $\mathrm{D}_{10}[28,35]$. A resistência está relacionada com vários fatores como temperatura, meio em que o micror- ganismo se encontra (mais complexo ou menos complexo como um meio liquido, por exemplo), atmosfera, tipos de células (Gram positiva ou Gram negativa), idade fisiológica das células.

Os alimentos irradiados têm sido bem recebidos pelos consumidores nos EUA [3], uma vez que o processo de irradiação, sozinho ou combinado com outros processos, é eficiente quando se deseja aumentar a segurança do alimento [9].

Tendo em vista que este processo reduz o número de microrganismos presentes em alimentos, entre eles os patogênicos, como é o caso de Salmonella spp e, em conseqüência, diminui os prejuizos social, devido à diminuição no número de doenças transmitidas por alimentos, e econômico decorrente da presença dessa bactéria em carne de frango e produtos derivados, os objetivos desta pesquisa foram determinar a radiossensibilidade de Salmonella Typhimurium ATCC 14028 em sobrecoxas de frango e sugerir uma dose de radiação que torne o produto adequado para o consumo humano.

\section{2 - MATERIAL E MÉTODOS}

\section{1 - Material}

Microrganismo: foi empregada a cepa Salmonella Typhimurium ATCC 14028.

Amostras de alimento: durante o processo de radiação, foram utilizadas sete bandejas de sobrecoxas de frango.

Para análise de presença ou ausência de Salmonella em coxas de frango, foram utilizadas 20 amostras, cada uma composta por quatro coxas, adquiridas em feiras livres da cidade de São Paulo.

Fonte radioativa: Irradiador JS-7500 Nordium Inc, que utiliza fonte de cobalto 60 cuja taxa de dose variou de 0,5 a 0,6 kGy/hora.

\section{2 - Métodos}

\subsection{1 - Preparo do inóculo}

A partir de uma cultura de $20-24$ horas a $37^{\circ} \mathrm{C}$, em caldo tripticase-soja (TSB Oxoid, Bsingstoke, UK), de $S$. Typhimurium ATCC 14028, foram feitas diluições decimais em solução salina $(0,85 \%)$ até $10^{-4}$. Inoculou-se $1 \mathrm{~mL}$ desta diluição em $99 \mathrm{~mL}$ de TSB, que foi incubado a $37^{\circ} \mathrm{C}$ por 5 horas com agitação (170rpm) em agitador Superhom. A cada 30 minutos, retiravam-se $5 \mathrm{~mL}$ da cultura, procedia-se à diluição até $10^{-4}$ e semeava-se em ágar tripticase soja (Oxoid), para obtenção do número de unidades formadoras de colônias por $\mathrm{mL}$ do meio de cultura. Concluiu-se que com 2 horas e meia de agitação, era obtido o inóculo desejado de $10{ }^{4} \mathrm{UFC} / \mathrm{mL}$.

\subsection{2 - Preparo do alimento para ser submetido ao processo de irradiação}

As bandejas contendo sobrecoxas de frango, adquiridas em supermercados da cidade de São Paulo, foram abertas em fluxo laminar e cada 4 sobrecoxas, escolhi- 
das aleatoriamente, foram transferidas para uma bandeja plástica. Sobre cada lado de cada uma das sobrecoxas, foi dispensado $0,125 \mathrm{~mL}$ de uma cultura de $10^{4} \mathrm{UFC} / \mathrm{mL}$ de $S$. Typhimurium ATCC 14028. Após 10 minutos de espera para aderência do microrganismo à superficie das sobrecoxas de frango, as bandejas foram embaladas com filme PVC transparente e transportadas, em caixas de material termoisolante com gelo, para a planta de irradiação.

\subsection{3 - Processo de irradiação}

Sete conjuntos de 8 bandejas foram submetidos, em datas diferentes, às seguintes doses de radiação: $0,12 \pm$ $0,02 \mathrm{kGy} ; 0,25 \pm 0,02 \mathrm{kGy} ; 0,37 \pm 0,03 \mathrm{kGy} ; 0,50 \pm 0,03 \mathrm{kGy}$;

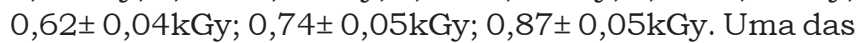
bandejas não foi submetida à irradiação. O experimento foi realizado em 6 ocasiões diferentes.

A irradiação foi realizada em canal experimental de irradiador JS-7500 Nordium Inc. (Kanata, Canadá), que utiliza uma fonte de ${ }^{60} \mathrm{Co}$, cuja taxa de dose variou de 0,5 a $0,6 \mathrm{kGy} /$ hora. A calibração do canal foi realizada com dosimetro "Red Perspex", padronizado pelo "National Physics Laboratory", laboratório padrão da Inglaterra.

\subsection{4 - Determinação do valor $D_{10}$ de $S$. Typhimurium ATCC 14028 em sobrecoxas de frango}

Determinação do Número Mais Provável (NMP) de $S$. Typhimurium ATCC 14028, em sobrecoxas de frango, após terem sido submetidas a diferentes doses de radiação [25].

As sobrecoxas irradiadas foram transportadas para o laboratório, em caixa de material termoisolante e com gelo, onde foram pesadas, lavadas e massageadas com Âgua Peptonada Tamponada $0,1 \%(\mathrm{v} / \mathrm{v})$. A partir deste lavado foram feitas diluições decimais seriadas até $10^{-3}$. As diluições e a amostra sem diluir foram inoculadas em cinco séries de três tubos da seguinte maneira: série 1: $10 \mathrm{~mL}$ do lavado em $10 \mathrm{~mL}$ de TSB, concentração dupla; série 2: $1 \mathrm{~mL}$ do lavado em $10 \mathrm{~mL}$ de TSB, concentração simples; série 3: $1 \mathrm{~mL}$ da diluição $10^{-1}$ em $10 \mathrm{~mL}$ de TSB, concentração simples; série 4: $1 \mathrm{~mL}$ da diluição $10^{-2} \mathrm{em}$ $10 \mathrm{~mL}$ de TSB, concentração simples e série $5: 1 \mathrm{~mL}$ da diluição $10^{-3}$ em $10 \mathrm{~mL}$ de TSB . Os tubos foram incubados a $37^{\circ} \mathrm{C} / 24 \mathrm{~h}$. A partir dos tubos positivos (com turvação), um inóculo foi semeado na superfície de placas com Âgar Sulfito de Bismuto (Oxoid) que foram incubadas a $37^{\circ} \mathrm{C} / 24 \mathrm{~h}$. Até 3 colônias, com características de Salmonella $\mathrm{spp}$, foram submetidas aos testes bioquimicos nos meios EPM, MILi e Citrato, que foram incubados a $37^{\circ} \mathrm{C} / 24 \mathrm{~h}$. Posteriormente, as colônias com reações tipicas para Salmonella spp nesses meios, foram confirmadas com soros somático e flagelar polivalentes (PROBAC do Brasil).

Determinação do Número Mais Provável (NMP) de Salmonella spp em sobrecoxas de frango adquiridas em feiras livres da cidade de São Paulo [25].

As sobrecoxas irradiadas foram pesadas, lavadas com água peptonada tamponada $0,1 \%(\mathrm{v} / \mathrm{v})$ e massageadas.
A partir deste lavado foram feitas diluições decimais seriadas até $10^{-1}$. As diluições e a amostra sem diluir foram inoculadas em três séries de três tubos contendo TSB. Os tubos foram incubados a $37^{\circ} \mathrm{C} / 24$. Um $\mathrm{mL}$ dos tubos considerados positivos (com turvação), foi transferido para tubos contendo $10 \mathrm{~mL}$ de Caldo Tetrationato e, paralelamente, transferiu-se três gotas de $30 \mathrm{~mL}$ cada, para placas com Meio Modificado Rappaport Vassiliadis semi-sólido. Ambos os meios foram incubados a $42^{\circ} \mathrm{C}$ por 24horas. A partir de cada tubo contendo Caldo Tetrationato e placas com o Meio Modificado Rappaport Vassiliadis que apresentavam uma zona turva de migração em volta da colônia, semeou-se em placas de Âgar Bismuto de Sulfito, que foram incubadas a $37^{\circ} \mathrm{C} / 24 \mathrm{~h}$. As colônias com caracteristicas de Salmonella spp foram confirmadas com os testes bioquímicos em meios ágar tríplice açúcar ferro (TSI) e ágar lisina ferro (LIA), EPM, MiLi e Citrato e com soros somático e flagelar polivalentes (PROBAC do Brasil).

\subsection{5 - Determinação do valor $D_{10}$ de Salmonella em sobrecoxa de frango}

O valor $D_{10}$ foi determinado através da análise de regressão linear simples. Segundo IAEA [14], a cinética de morte microbiana está relacionada diretamente com as doses de irradiação aplicadas segundo uma lei exponencial do tipo: $\mathrm{N}=\mathrm{N}_{\mathrm{o}}[10]^{-\mathrm{D} / \mathrm{D} 10}$, onde $\mathrm{N}_{\mathrm{o}}$ é a contagem inicial de microrganismos; $\mathrm{N}$ é igual a contagem de microrganismos sobreviventes após a aplicação da dose D; D é a dose de irradiação aplicada e $\mathrm{D}_{10}$ é a dose de irradiação necessária para a destruição de 90\% da população microbiana.

Essa equação pode ser linearizada para a seguinte forma:

$\log N=\log N_{0}-\left(1 / D_{10}\right) D$

que corresponde a uma reta do tipo $y=a+b x$, onde:

$\mathrm{a}=\log \mathrm{N}_{\mathrm{o}}=$ coeficiente linear de regressão; $\mathrm{b}=1 / \mathrm{D}_{10}=$ coeficiente angular de regressão. $\mathrm{O}$ valor $\mathrm{D}_{10}$ foi calculada como o inverso positivo do coeficiente angular da regressão: $\mathrm{D}_{10}=1 / \mathrm{b}$

\section{3 - RESULTADOS E DISCUSSÃO}

Na Tabela 1 são apresentadas as populações de sobreviventes (log NMP/g) de S. Typhimurium ATCC 14028, inoculada em sobrecoxas de frango submetidas a diferentes doses de radiação gama. As lacunas existentes nessa tabela são devido ao programa estatístico aplicado aos resultados obtidos, denominado Método dos Quadrados Mínimos.

Na Figura 1 são apresentadas as curvas de regressão linear para $S$. Typhimurium inoculada em sobrecoxas de frango.

O valor $\mathrm{D}_{10}$ encontrado para $S$. Typhimurium ATCC 14028 inoculada em sobrecoxas de frango variou de 
0,24kGy a 0,48kGy. Esses valores são menores do que os encontrados para essa bactéria quando inoculada em caldo tripticase soja $(0,16 \mathrm{kGy}$ a $0,21 \mathrm{kGy}$, dados não apresentados). Tal fato pode ser explicado pela complexidade da composição do alimento em relação ao meio liquido, isto é, maior teor de lipídeos, proteínas, carboidratos, etc, que competirão com a bactéria pelos radicais livres formados durante a irradiação. Em um meio de cultura líquido, que apresenta uma composição menos complexa do que um alimento, os radicais livres produzidos atingirão preferencialmente a bactéria, tendo assim um efeito letal maior.

Os valores de $\mathrm{D}_{10}$ encontrados em sobrecoxas de frango para Salmonella estão de acordo com valores obtidos por outros autores [4, 12, 27, 29].
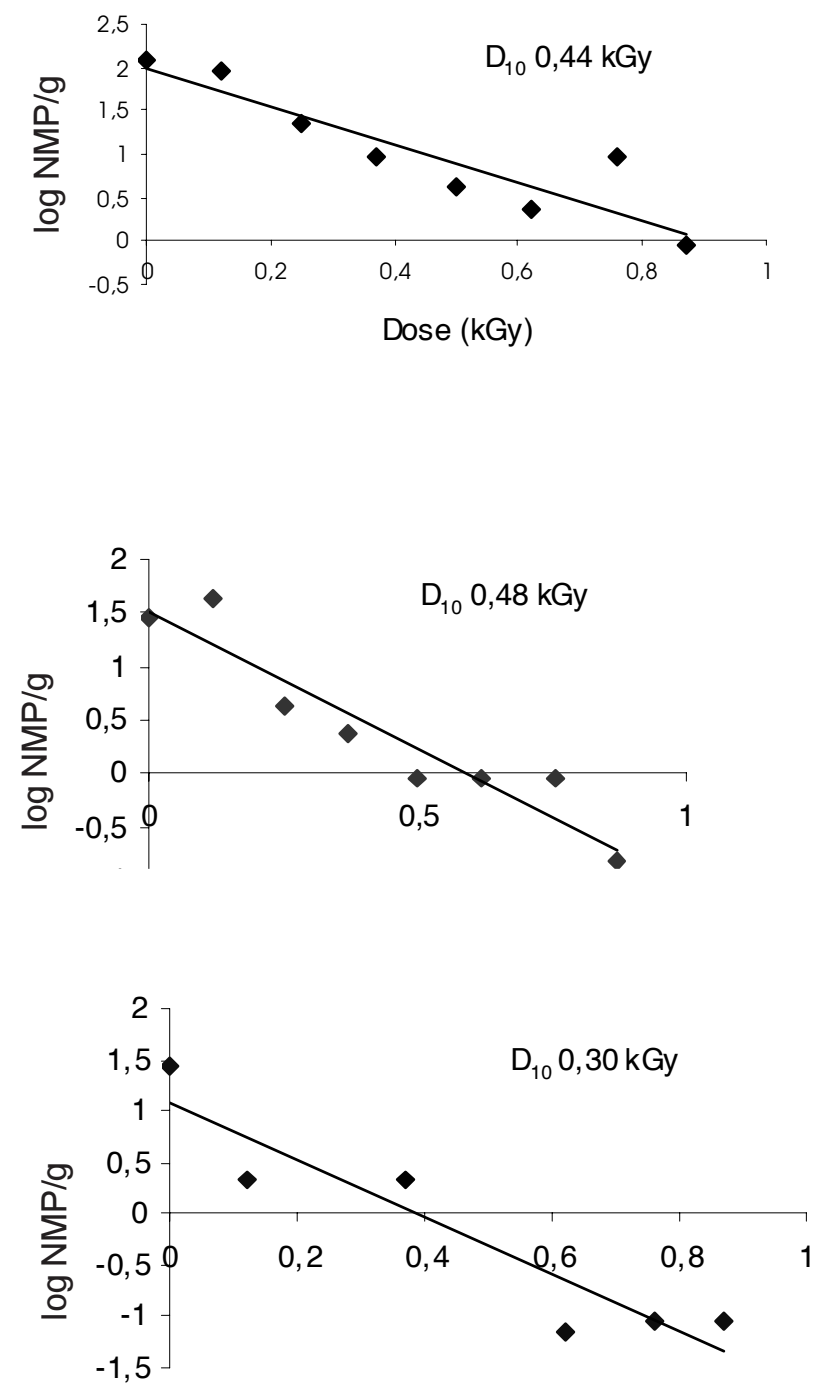

Dose (kGy)

TABELA 1. População de sobreviventes $(\log \mathrm{NMP} / \mathrm{g})$ de $S$ Typhimurium ATCC 14028, inoculada em sobrecoxas de frango submetidas a diferentes doses de radiação gama.

\begin{tabular}{ccccccc} 
Dose & \multicolumn{7}{c}{ população de sobreviventes (log NMP/g) } \\
$(\mathrm{kGy})$ & $\mathrm{A}^{*}$ & $\mathrm{~B}^{*}$ & $\mathrm{C}^{*}$ & $\mathrm{D}^{*}$ & $\mathrm{E}^{*}$ & $\mathrm{~F}^{*}$ \\
0,0 & 1,43 & 1,46 & 2,18 & 2,18 & 2,32 & 2,08 \\
$0,12 \pm 0,02$ & 0,32 & 1,63 & 1,63 & 2,18 & 0,63 & 1,97 \\
$0,25 \pm 0,02$ & & 0,63 & 0,97 & 0,18 & $-0,70$ & 1,36 \\
$0,37 \pm 0,03$ & 0,32 & 0,36 & 0,63 & 0,18 & $-0,70$ & 0,97 \\
$0,50 \pm 0,04$ & & $-0,04$ & $-0,70$ & 0,36 & $-1,0$ & 0,63 \\
$0,62 \pm 0,04$ & $-1,15$ & $-0,04$ & $-0,15$ & $-0,04$ & 0,56 & 0,36 \\
$0,74 \pm 0,05$ & $-1,04$ & $-0,04$ & $-0,82$ & $-0,04$ & $-1,52$ & 0,97 \\
$0,87 \pm 0,05$ & $-1,04$ & $-0,82$ & $-1,52$ & $-1,52$ & $-1,52$ & $-0,04$
\end{tabular}

${ }^{*} \mathrm{~A}, \mathrm{~B}, \mathrm{C}, \mathrm{D}, \mathrm{E}$ e $\mathrm{F}=$ seis experimentos independentes.

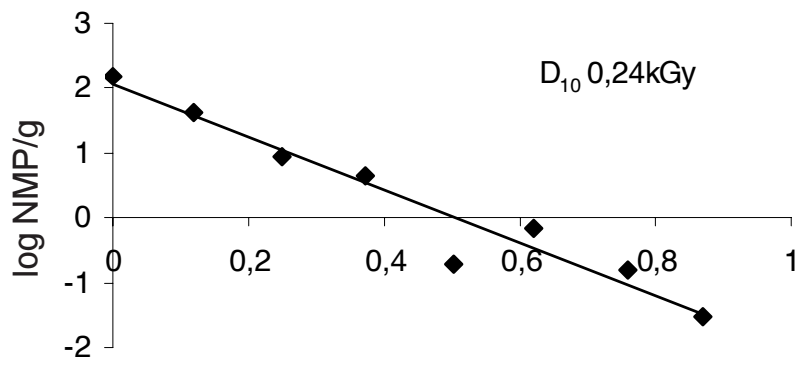

Dose (kGy)
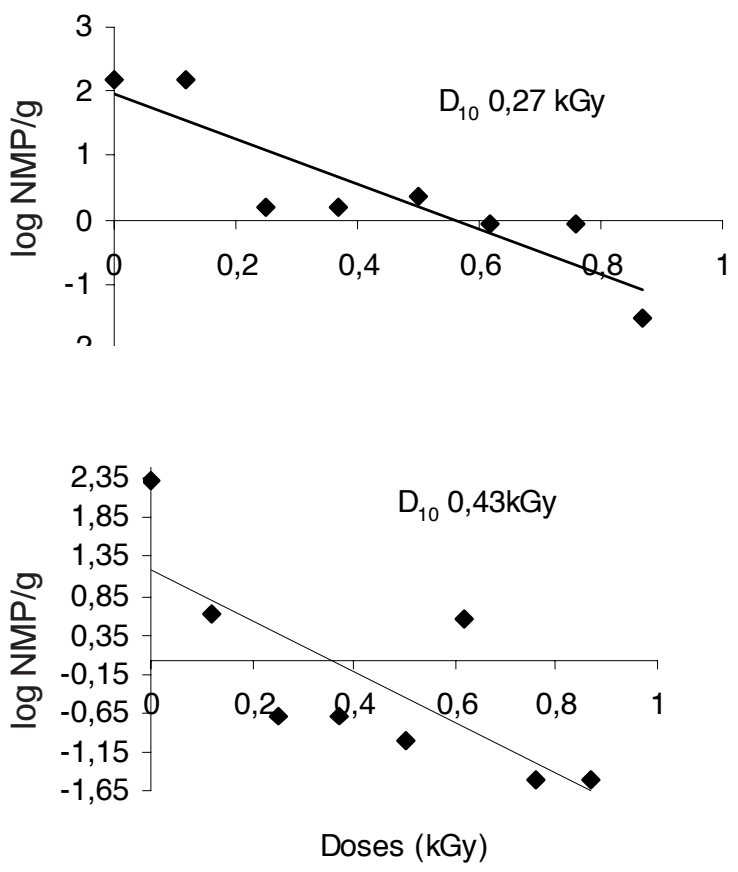

FIGURA 1. Curva de sobreviventes de Salmonella Typhimurium ATCC 14028 inoculada em sobrecoxas de frango expostas à radiação gama nas doses de $0,1 \mathrm{kGy} ; 0,2 \mathrm{kGy}$; 0,3kGy; 0,5kGy; 0,6kGy; 0,7kGy e 0,8kGy. 
GRANT \& PATTERSON [12] constataram que os valores de $\mathrm{D}_{10}$ para $S$. Typhimurium incoulada em rosbife, molho, couve-flor, batata assada e purê de batata, irradiada e recuperada em meio seletivo foram de 0,507kGy; 0,371kGy; 0497kGy; 0,421kGy e 0,403kGy, respectivamente.

CLAVERO et al [4] verificaram que os valores de $\mathrm{D}_{10} \mathrm{em}$ carne moida para E. coli O157: $\mathrm{H} 7$ variaram de $0,241 \mathrm{kGy}$ a 0,307kGy; para Campylobacter de 0,175kGya 0,235 kGy e para Salmonella estiveram entre 0,618kGy e 0,800kGy.

SHAMSUZZAMAN et al. [27] estudaram a radiorresistência de duas linhagens de Salmonella Typhimurium (ATCC 13311 e K1-2B), resistentes ao ácido nalidixico, inoculadas em tampão fosfato, caldo nutriente e coxas de frango. Os valores encontrados, respectivamente, foram de 0,20kGy; 0,57kGy e 0,53kGy para a linhagem ATCC 13311 e 0,21kGy; 0,40kGy e 0,32kGy para a linhagem K1-2B. Foi constatado, também, que as duas linhagens eram mais sensiveis à radiação quando em tampão fosfato do que quando em caldo nutriente. A sensibilidade das duas linhagens de $S$. Typhimurium quando inoculadas em frango esteve entre a dos outros dois meios. No caso da carne de frango, o efeito protetor de seus componentes químicos contribuíram para a menor sensibilidade das duas linhagens quando comparadas com a observada em tampão fosfato.

THAYER et al. [29] determinaram o valor $\mathrm{D}_{10}$ de seis espécies de Salmonella inoculadas em tampão fosfato, caldo infusão de cérebro e coração e carne de frango mecanicamente desossada, sob diferentes temperaturas e ausência ou presença de oxigênio. A resistência dos microrganismos foi maior quando inoculados em carne de frango. A realização do processo de irradiação na presença ou ausência de oxigênio não apresentou diferença nos valores $\mathrm{D}_{10}$ das bactérias. Foi observada, no entanto, uma maior resistência dos microrganismos quando irradiados no frango congelado.

No entanto, para Listeria monocytogenes, os valores de $D_{10}$ em carne de frango são maiores que os de Salmonella 0,471kGy a 0,533kGy [23]. Essa diferença é explicada pelo fato dessa bactéria ser Gram positiva o que lhe confere maior resistência à radiação.

Fatores secundários como meios de crescimento e condições de incubação, para se estimar a população de microrganismos sobreviventes após o processo de irradiação, influenciam no valor $\mathrm{D}_{10}$ dos microrganismos [32]. Em estudo realizado por CORRY et al. [5], foi constatado que a recuperação de $S$. Typhimurium irradiada dependia do emprego do caldo de enriquecimento adequado, assim como da temperatura e tempo de incubação e meio para isolamento. No presente estudo, foi utilizada a técnica do Número Mais Provável ( NMP) para enumeração das células de S. Typhimurium ATCC 14028 sobreviventes ao processo de irradiação, uma vez que essa técnica permite a detecção e enumeração de Salmonella spp e de outros microrganismos mesmo quando presentes em números muito baixos no alimento.

Vários autores [4, 7, 17, 18, 21, 30, 31, 32, 33], concluiram que doses entre $1,5 \mathrm{kGy}$ a $3,0 \mathrm{kGy}$ são suficientes para inativar Salmonella spp em carne de frango.
No entanto, para sugerirmos uma dose de radiação para o tratamento de um produto a fim de torná-lo microbiologicamente adequado ao consumo humano, deve ser considerado, juntamente com o valor $\mathrm{D}_{10}$ do microrganismo, o nivel de contaminação do produto e para quanto este nivel deve ser reduzido.

A INTERNATIONAL COMMISSION ON MICROBIOLOGICAL SPECIFICATION FOR FOOD [15] estabelece como nivel tolerável para o consumidor para um número de doenças transmitidas por alimentos a ausência efetiva de doença, isto é, <0,1 caso por $100.000-10^{-6}$, número que será tomado como referência neste traba1ho.

Outro fator a ser considerado é que não é possivel tornar um alimento totalmente livre de salmonela uma vez que a sua resposta à irradiação é exponencial. Portanto, deve-se reduzir o seu número para valores que sejam compativeis com o chamado risco aceitável.

De acordo com os resultados desta pesquisa, o valor $\mathrm{D}_{10}$ para $S$. Typhimurium em sobrecoxa de frango foi de $0,48 \mathrm{kGy}$ e a população mais alta encontrada desse microrganismo nesse alimento foi $0,4 \mathrm{NMP} / \mathrm{g}$. O consumo de carne de frango no Brasil é de $23 \mathrm{~kg} /$ habitante/ano [20] ou seja, em média, 63g/dia.habitante.

\section{Teremos então:}

1. contaminação do frango: 63g/dia.hab. x 0,4 NMP/ $\mathrm{g}=25,2 \mathrm{NMP} /$ dia.hab.

2. dose recomendada

Considerando que o número de microrganismos do gênero Salmonella necessário para causar a doença pode ser tão baixo quanto $10^{2} \mathrm{UFC} / \mathrm{g}$ [6], em $2,3 \times 10^{10} \mathrm{~g}$ teremos:

$10^{2} \mathrm{UFC} / \mathrm{g}: 2,3 \times 10^{10} \mathrm{~g}=0,43 \times 10^{-9} \mathrm{UFC}$

Como o valor mais alto do NMP encontrado nas amostras de sobrecoxas de frango analisadas foi de 0,4 ou $4 \mathrm{x}$ $10^{-1} \mathrm{NMP} / \mathrm{g}$, o fator de redução será:

$4 \times 10^{-1}: 4,3 \times 10^{-9}=0,93 \times 10^{8}$

Se o valor $\mathrm{D}_{10}$ máximo encontrado em sobrecoxas de frango é de $0,48 \mathrm{kGy}$, a dose recomendada é equivalente a:

fator de redução que é 8 x 0,48kGy = 3,84kGy.

\section{4 - CONCLUSÕES}

Os resultados obtidos, nas condições desta pesquisa, permitem sugerir a dose minima de 3,8kGy para irradiação de sobrecoxas de frango, a fim de se obter um produto adequado para o consumo humano, quanto à presença de Salmonella Typhimurium. No entanto, para uma aplicação comercial essa dose deverá ser validada. 


\section{5 - REFERÊNCIAS}

[1] ANDREWS, L.S., AHMEDNA, M., GRODNER, R.M., LIUZZO, J. A ., MURANO, P.S., MURANO, E.a ., RAO, R.M., SHANE, S., WILSON, P.W. Food preservation using ionizing radiation. Rev. Environ. Contam. Toxicol., v. 154, p.1-53, 1998.

[2] BRASIL. Resolução RDC n.21, de 26 de jan. 2001. Diário Oficial da União, Brasília, n.20-E, 29 de janeiro de 2001. Seção 1, p.35. [Agência Nacional de Vigilância Sanitária aprova o Regulamento Técnico para Irradiação de Alimentos].

[3] BRUHN, C.M. Consumer perceptions and concerns about food contaminats. Adv. Exp. Med. Biol., v.459, p. 1-7, 1999.

[4] CLAVERO, M. R. S., MONK, J. D., BEUCHAT, L. R., DOYLE, M. P., BRACKETT, R. E. Inactivation of Escherichia coli O157 : H7; Salmonellae and Campylobacter jejuni in raw ground beef by gamma irradiation. Appl. Environ. Microbiol., v.60, n.6, p.2069 - 2075, 1994.

[5] CORRY, J. E. L., KiTChell, A. G., ROBERTs, T. A Interactions in the recovery of Salmonella Typhimurium damaged by heat or gamma radiation. J. appl. Bacteriol., v.32, p.415 - 428, 1969.

[6] D'AOUST, J. -Y. Salmonella and the international food trade. Int1. J. Food Microbiol., v. 13, p.207 - 216, 1994.

[7] DICKSON, J. S. Radurization - The pasteurization of foods by ionizing radiation. J. Food Prot., v. 58, suplemment n.58 p. $1-70,1995$

[8] DIEHL, J. F. Safety of Iradiated Foods. New York: Marcel Dekker, Inc, 1990, 345p.

[9] FARKAS, J. Irradiation as a method for decontamination food. A review. Intl. J. Food Microbiol., v. 44, p. 189-204, 1998.

[10] GELLI, D.S; JAKABI, M; SAKATA, H; FERNANDES, S.A; TRAVECCHIO, A .T; PERESI, J.T.M; FREITAS, ${ }^{\mathrm{a} M}$; ESPER, M.R.N.R; PISANI, B; SIMÕES, M; PACHECO, M.A.S.R., FONSECA, Y.S.K., KAKU, M., MARTINS, A.M.B., RIBEIRO, E.G.A ., CASTRO, M.T.F., FAUSTINO, J.S., TANAKA, A .Y., GOMES, S.M.M. Salmonelas isoladas de alimentos no período de 1985-1996 no estado de São Paulo, Brasil. In: CONGRESSO LATINO-AMERICANO DE MICROBIOLOGIA DE ALIMENTOS (COMBHAL), 5, Águas de Lindóia, 1998. Livro de Resumos. São Paulo: SBM, 1998. P.105, res.Q.101.

[11] GOULD , G.W. Methods for preservation and extension of shelf life. Int1. J. Food Microbiol., v.33, p.51-64, 1996.

[12] GRANT, I. R., PATTERSON, M. F. Sensitivity of foodborne pathogens to irradiation in the components of a chilled ready meal. Food Microbiol., v.9, p.95-103, 1992.

[13] HELSON, S. Estimating the incidence of food-borne Salmonella and effectiveness of alternative control measures using the Dephi method. Int1. J. Food Microbiol., v.33, p.195-204, 1997.

[14] IAEA (International Atomic Energy Agency) Training manual on food irradiation technology and techniques. Vienna: Technical reports series No.114 $2^{\text {nd }}$ ed., 1982, p.3-101.

[15] INTERNATIONAL COMMISSION ON MICROBIOLOGICAL SPECIFICATION FOR FOODS. Microorganisms in foods. v.7 Microbiological testing in food safety management. New York, Kluwer Academic/Plenum Publishers. 2002, p.23-43.

[16] JAKABI, M., BUZZO, A .A ., RISTORI, C.A ., TAVECHIO, A .T., SAKUMA, H., PAULA, A .M.R., GELLI, D.S., Observações laboratoriais sobre surtos alimentares de Salmonella sp, ocorridos na grande São Paulo, no período de 1994 a 1997. Rev. Inst. Adolfo Lutz., v.58, p.47-51, 1999.

[17] KATTA, S. R., RAO, D. R., SUNK, G. R., CHAWAN, C. B. Effect of gamma irradiation of whole chicken carcasses on bacterial loads and fatty acids. J. Food Sci., v.56, n.2, p.371-372, 1991.

[18] LESCANO, G., NARVAIZ, P., KAIRIYAMA, E., KAUPERT, N. Effect of chicken breast irradiation on microbiological, chemical and organoleptic quality. Food Sci.Technol., v.24, p.130-134, 1991.

[19] LOAHARANU, P. Irradiation as a cold pasteurization process of food. Annu Rev. Nutr., v. 17, p.255-275, 1997.

[20] MASTROGIACOMO, V. F. O mercado da carne. XI Simpósio Aginomoto de Tecnologia da Carne, Foz do Iguaçú, 06 09 Maio, 1997

[21] MORETTI, R. H. Cost - Benefit of poultry irradiation in Brazil. In: Cost-benefit aspects of food irradiation processing. Vienna: IAEA, 1993. [Proceedings of a symposium in Provence, 1993 ( IAEA-SM-328/68)].

[22] Organización Mundial de la Salud. Organización Panamericana de la Salud, Instito Panamericano de Protection de Alimentos y Zoonosis, Inppaz OPS/OMS. Informe sobre el Sistema de Informacion Regional para la Vigilancia Epidemiologica de las Enfermedades Transmitidas por Alimentos. (SIRVE-ETA), 1999.

[23] PATTERSON, M. Sensitivity of Listeria monocytogenes to irradiation on poultry meat and in phosphate-buffered saline. Lett. Appl. Microbiol., v. 8, p. 181 - 184, 1989.

[24] PAULI, G. H., TARANTINO, L. M. FDA regulatory aspects of food irradiation. J. Food Prot., v.58, n.2, p.209-2 12, 1995.

[25] PEELER, J.T., HOUGHTBY, G.A ., RAINOSEK, A. P. The Most Probable Number Technique. In: VANDERZANT, C., SPLITTSTOESSER, D.F. Compendium of Methods for the Microbiological Examitation of Foods., Washington: APHA, 1992, p.105-120.

[26] PUBLIC HEALTH LABORATORY SERVICE (PHLS). Infectious intestinal diseases general outbreaks, England and Wales, by organism, 1992-1998. [Online]. Avaliable: http:/www.phls.co.uk/facts/iid-fO 1.htm [1999, Sept. 14].

[27] SHAMSUZZAMAN, K., GOODWIN, M., GEORGE, I., SINGH, H. Radiation survival of two nalidixic acid resistant strains of Salmonella Typhimurium in various media. Radiat. Phys. Chem., v.34, n.6, p.985-989, 1989.

[28] TALLENTIRE, A. The spectrum of microbial radiation sensitivity. Radiat. Phys. Chem., v. 15, p.83-89, 1980.

[29] THAYER, D. W., BOYD, G., MULLER, W.S., LIPSON, C.A., HAYNE, W.C., BAER, S.H. Radiation resistance of Salmonella. J. Ind. Microbiol., v.5, p.383-390, 1990.

[30] THAYER,D. W., DICKERSON, C. Y., RAO, D. R., BOYD, G., CHAWAN, C. B. Destruction of Salmonella Typhimurium on chicken wings by gamma radiation. J Food Sci., v.57, n.3, p.586-589, 1992.

[31] THAYER, D. W., BOYD, G. Survival of Salmonella Typhimurium ATCC 14028 on the surface of chicken 1 egs or in mechanically deboned chicken meat gamma irradiated in air or vacuum at temperatures of -20 to $+20{ }^{\circ} \mathrm{C}$. Poultry Sci., v.70, n.4, p.1026-1033, 1991.

[32] THAYER, D. W; BOYD, G; FOX, J. B; LAKRITZ, L; HAMPSON, J. W. Variations in radiation sensitivity of foodborne pathogens associated with the suspending meat. J. Food Sci., v. 60, n. 1, p. 63 - 67, 1995.

[33] THAYER, D. W; BOYD, G. Elimination of Salmonella and Staphylococcus aureus from bison, ostrich, alligator and caiman meat by gamma irradiation. Supplement of $\mathbf{J}$. Food Prot. v. 59, p. 1 - 70, 1996.

[34] TODD, E. C. D. Preliminary estimates of costs of foodborne disease in the United States. J. Food Prot., v.52, n.8, p.595-60 1, 1989.

[35] URBAIN, W. M. Food irradiation. Orlando: Academic Press, 1986. 351p.

\section{6 - AGRADECIMENTOS}

Esta pesquisa foi realizada com auxílio da Fundação de Amparo à Pesquisa do Estado de São Paulo (FAPESP 96/0336-1) 